\title{
OTIONOMTCS
}

Revista de economía, empresa y sociedad

Dosier «Vectores de sostenibilidad: visiones desde la economía»

Coordinador: Albert Puig Gómez

REFLEXIONES A PARTIR DE UNA REVISIÓN DE LAS APORTACIONES DE LA ECONOMÍA

\section{¿Fs posible un desarrollo económico y social sostenible? Una nota crítica sobre el "valor" de los ODS}

\section{Joan Torrent-Sellens}

Catedrático de Economía en los Estudios de Economía y Empresa de la UOC

RESUMEN Este artículo analiza la conexión que ha realizado la economía científica entre el desarrollo económico y la sostenibilidad social. Partiendo de la idea clásica del valor en el capitalismo, el artículo revisa las principales aportaciones que la economía clásica, neoclásica, heterodoxa y las síntesis modernas han efectuado sobre la posibilidad de un desarrollo económico socialmente sostenible. A partir de esta revisión, se llega a la necesidad de construir una nueva economía del valor sostenible y se analizan sus principales dimensiones, en especial el papel que deberían jugar las empresas, los mercados y el gobierno. En la investigación sobre el encaje entre las nuevas formas sostenibles de generar valor y los objetivos de desarrollo sostenible (ODS), los resultados obtenidos son desfavorables. Los ODS deben modificar sustancialmente su aproximación y metodología para poder avanzar hacia un valor económico más socialmente sostenible.

PALABRAS CLAVE valor; teoría del valor; economía clásica; economía neoclásica; economía del desarrollo; objetivos de desarrollo sostenible 


\title{
Is sustainable economic and social development possible? A critical note on the "value" of the SDGs
}

\begin{abstract}
This article analyses the connection that scientific economics has made between economic development and social sustainability. Starting from the classical idea of value in capitalism, the article reviews the main contributions that classical, neoclassical, heterodox and modern economic syntheses have made on the possibility of a socially sustainable economic development. From this review, the need to build a new sustainable value economy is identified and its main dimensions are analysed, especially the role that firms, markets and government should play. In our research on the fit between new sustainable ways of generating value and the Sustainable Development Goals (SDGs), the results obtained are unfavourable. The SDGs must substantially modify their approach and methodology to move towards a more socially sustainable economic value.
\end{abstract}

KEYWORDS value; theory of value; classical economics; neoclassical economics; development economics; sustainable development goals (SDGs)

\section{Introducción}

A mediados de la década de 1940, un joven hindú residente en Daca, la actual capital de Bangladesh, vivió de primera mano los horrores de la explosión violenta entre hindús y musulmanes que aconteció en el período de lucha, independencia y posterior creación de la India y Pakistán. Estando el joven, de origen bengalí, en su jardín de la zona hindú de la ciudad, otro joven, un jornalero musulmán llamado Kader Mia, entró en la propiedad buscando ayuda, y gravemente herido por las palizas y apuñalamientos que había recibido por haber entrado en «zona prohibida» para alguien de su confesión. De camino al hospital Kader le contó a nuestro joven que, a pesar de las peticiones de su familia, decidió dar el paso porque no tenían nada que comer y debía arriesgarse para ganar dinero y alimentar a su familia. Pocas horas después Kader murió como resultado de sus heridas, lo que marcó profundamente la manera de pensar y aproximarse a uno de los grandes temas de la economía -yo diría más, una de las razones de ser de la economía como ciencia-: la pobreza y el desarrollo. Nuestro joven protagonista hindú se llamaba Amartya Sen (1933). Muchos años más tarde este joven se convertiría en uno de los economistas más lúcidos, reputados e influyentes en el análisis de la pobreza y el desarrollo económico. Llegó a ser el impulsor de la idea del "desarrollo humano» y obtuvo el Premio Nobel de Economía en 1998.

Alrededor de una década más tarde del suceso en Daca, concretamente el 6 de marzo de 1957, en Acra, una bonita ciudad de la Costa de Oro en el Golfo de Guinea, un pensador y político panafricanista, llamado Kwame Nkrumah, declaró a Ghana libre para siempre. El nuevo país se convirtió, de este modo, en la primera nación africana colonizada que conseguía su independencia -en su caso del Imperio británico-, lo que abrió las puertas a todo el proceso de descolonización que experimentaron los países africanos durante la década de 1960. El equipo económico del presidente Nkrumah contaba con el asesoramiento de otro luchador y rompedor de barreras raciales. William Arthur Lewis (1915-1991) nació en otra colonia pobre del Imperio británico, en la isla caribeña de Santa Lucía. Quería ser ingeniero, pero obtuvo su graduación con honores en Economía por la Universidad de Londres a finales de la década de 1930 -la única disciplina a la que pudo optar a beca debido a la discriminación racial de aquella época- y, en cierta ocasión, fue rechazado por The Economist por el color de su piel. Lejos de amedrentarse, perseveró en su carrera académica, y en 1938 fue la primera persona de ascendencia africana y piel negra en ser nombrada profesor en la prestigiosa London School of Economics. Más tarde, en 1979 y junto a otro luchador a contracorriente, el profesor de Chicago Theodore W. Schultz (1902-1998), recibió el Premio Nobel de Economía por sus aportaciones seminales sobre la economía del desarrollo. En la actualidad, sigue siendo el único Nobel de Economía de piel negra. 
Más o menos al tiempo que en Acra se declaraba la independencia de Ghana, ochenta y dos hombres habían llegado a Cuba desde México con la intención de derrocar al régimen dictatorial y corrupto de Fulgencio Batista e instaurar una república socialista de corte marxista. En grupo de los 82 se encontraban un joven abogado cubano, Ilamado Fidel Castro, y un médico argentino, llamado Ernesto Che Guevara. Ambos consideraban que la pobreza en América Latina era el resultado directo de la explotación que los países ricos, para el caso americano esencialmente Estados Unidos, ejercían sobre los países pobres. La idea de la explotación intencionada de un país hacia otro no estaba disponible en el ideario económico. La visión neoclásica seguía a pies juntillas los postulados de David Ricardo (1772-1823) y su teoría de la ventaja comparativa. Es decir, la idea de que el comercio internacional solo puede generar efectos positivos si los países se especializan en lo que saben producir mejor. Por su parte, el análisis marxista había configurado sus términos sobre la base de la explotación de clase. Únicamente la visión de un economista heterodoxo inglés, llamado John Hobson (1858-1940), había establecido unos primeros fundamentos de la relación «injusta» entre países. En su análisis del imperialismo, que recuperó su ímpetu a finales del siglo XIX y principios del XX, coincidiendo con la consolidación de las revoluciones industriales, Hobson creía que el imperialismo fue la tabla de salvación del capitalismo. La única manera de acabar con la tendencia natural del capitalismo hacia los excesos de ahorro y la explotación obrera es "conquistar» nuevos territorios, explotar sus recursos físicos y humanos -violentamente si es necesario- y consolidar el círculo virtuoso del capital a través de los monopolios comerciales, agrarios, industriales y financieros. Siguiendo postulados de esta aproximación, dos economistas, André Gunder Frank (1929-2005) y Raúl Prebisch (1901-1986) aportaron explicaciones plausibles a esta idea, aunque con soluciones muy diferenciadas. Frank nació en Berlín y su familia emigró a EE. UU. huyendo del nazismo. Estudió y se doctoró en Economía en la Universidad de Chicago, pero como resultado de sus incontables viajes por EE. UU. y América Latina pronto abandonó el tarro de las esencias de la economía neoclásica. Se convirtió quizás en uno de los principales críticos de la idea de las bondades per se del comercio internacional y asesoró a múltiples Gobiernos socialistas de América Latina durante las décadas de 1960 y 1970. Con el golpe de Estado de Augusto Pinochet en Chile se exilió de nuevo y volvió al país del que, curiosamente, también había emigrado por cuestiones políticas cuarenta años antes. Raúl Prebisch nació en Tucumán, al norte de Argentina, en el seno de una familia importante en los círculos literarios y culturales de la zona. Estudió Contaduría Pública en la Universidad de Buenos Aires y ejerció de profesor de Economía Política en esta. Combinó su actividad docente con una larga trayectoria política y de participación en instituciones económicas nacionales e internacionales. Fue gerente del Banco Central de la República Argentina y ocupó cargos muy relevantes en organizaciones económicas de Naciones Unidas, en especial la CEPAL (Comisión Económica de Naciones Unidas para América Latina) y la UNCTAD (Conferencia de las Naciones Unidas sobre Comercio y Desarrollo). A pesar de tener un diagnóstico parecido sobre los motivos de la pobreza y la falta de desarrollo económico en América Latina, las propuestas de política económica desarrollistas de Frank y Prebisch fueron muy distintas. Algunos dirán que antitéticas.

A pesar de sus diferencias vitales y de pensamiento, estos cuatro economistas tienen una cosa en común. Se trata de una visión amplia de lo que significa la pobreza y cuáles son sus posibles causas y soluciones. Para ellos, la pobreza es mucho más que la falta de recursos y bienes materiales. Entre otras, es una cuestión de justicia, de igualdad de oportunidades, de educación, de seguridad, de libertad política, de transparencia. En definitiva, y siguiendo la visión de Sen, del conjunto de «capacidades» que necesitamos para tener una buena vida. La visión económica principal sobre el desarrollo como instrumento principal para la superación de la pobreza no siempre ha sido la misma. De hecho, como toda la economía, ha ido fluctuando en forma de péndulo, dando bandazos entre las aproximaciones más favorables al mercado o a las intervenciones públicas. Sin embargo, lo que sí podemos afirmar con toda rotundidad es que el desarrollo y su sostenibilidad es un problema central de la economía, y por consiguiente es una cuestión de la que la economía científica se ha preocupado desde sus inicios. Situando la cuestión en los términos de este artículo, para responder a la pregunta de si es posible el desarrollo económico y social sostenible, y en concreto de si los objetivos de desarrollo sostenible (en adelante ODS) encajan bien y pueden ser de utilidad para alcanzar su propósito, tendremos que volver nuestra mirada hacia la economía. Como nos enseña la trayectoria y la vida de estos cuatro, y otros muchos, grandes economistas que se han preocupado y se preocupan por el desarrollo, no es posible aislar a la buena economía de la ecuación del desarrollo sostenible. Es evidente que para alcanzar una meta tan ambiciosa se necesitarán aportaciones y esfuerzos de todos los campos del saber científico y tecnológico, del mismo modo que serán necesarias las participaciones de todos los agentes y redes económicas y sociales. Pero una visión crítica desde la economía es indispensable para avanzar hacia esta meta. Precisamente, esta visión económica sobre el desarrollo 
económico y la sostenibilidad social, con una breve nota crítica sobre los ODS en estas dimensiones, es la que pretendo ejercer brevemente en este artículo: «Al César lo que es del César».

Vaya por delante que en este artículo no abordaremos con la profundidad que se merece la cuestión de la sostenibilidad ambiental. En primer lugar, porque la extensión del artículo -y mi capacidad de síntesis- dan para lo que dan. Y, en segundo lugar, y muy lamentablemente, porque la economía científica se ha preocupado mucho menos de sus implicaciones ambientales que de sus implicaciones sociales. Ello no significa que no haya suficientes teorías, autores, escuelas y evidencia empírica para tratar la cuestión como se merece. Creo, sinceramente, que esto es un tema para otro artículo.

\section{Valor, desarrollo económico, y sostenibilidad social: ¿qué nos dice el análisis económico?}

El debate sobre la relación entre desarrollo económico y sostenibilidad social es prácticamente tan viejo como la propia economía. Ya los economistas clásicos, como Adam Smith (1723-1790), David Ricardo (1772-1823) o Karl Marx (18181883), se preguntaron por las causas y las consecuencias, en términos de pobreza y justicia social, de la dinámica económica. Los tres contribuyeron al desarrollo de la teoría del valor-trabajo. Las tres dimensiones esenciales de la teoría del valor -entendido como la producción de un bien o servicio adicional- son la producción -cómo se producen los bienes y servicios-, la distribución -cómo se comparten los bienes y servicios- y la reinversión -cómo se reparten los excedentes generados entre salarios, beneficios y rentas-. La teoría del valor establece los límites de producción, es decir, las divisiones entre las actividades productivas, las que generan valor, y las improductivas, las que extraen valor. Por consiguiente, la teoría del valor es de gran utilidad para el análisis económico porque está pensada para distinguir entre la creación de valor o riqueza y la extracción de valor o rentas. Es decir, entre aquellos métodos de combinación de factores para producir nuevos o más bienes y servicios -lo que hoy llamaríamos como análisis de la productividad y modelos de crecimiento económico- y aquellas actividades de circulación o de producción que tienen como objetivo generar rentas derivadas del poder políico o de mercado -lo que hoy llamaríamos el análisis del bienestar y la desigualdad-. Aunque por causas distintas, los tres economistas clásicos por excelencia consideraron que el principal creador de riqueza de la economía en la naciente época industrial era el trabajo de sus empleados productivos.

Para Smith la creación de valor procedía de la especialización del trabajo, de la búsqueda del interés individual como método para alcanzar el interés colectivo y de la «mano invisible» del mercado. Actuando en conjunción estos tres impulsores permitían el desarrollo de las fuerzas productivas de la economía por encima de los intereses improductivos representados por las actividades comerciales y terciarias, así como por los intereses de la aristocracia, la nobleza y el Gobierno. Ricardo expandió el pensamiento de Smith y se preocupó de algo poco presente en el análisis del economista escocés: la distribución del valor generado, especialmente su repartición entre salarios, beneficios y rentas. En su análisis de la distribución, y anticipando premisas del pensamiento marxista, Ricardo criticó con dureza a terratenientes y aristócratas -los verdaderos responsables de la extracción de rentas- y alabó a los empresarios capitalistas industriales, que eran capaces de orientar su consumo de forma productiva, es decir, invirtiendo su capital y beneficios para reproducir el sistema productivo y contratar empleados. De este modo, Ricardo redefinió los límites de la producción, ya no en función de determinados sectores o actividades, sino en función de la utilización del valor generado. Cuando el excedente generado era utilizado para gastos productivos, como la inversión en bienes de equipo o la contratación de empleados, la actividad era productiva. Si los excedentes no se empleaban en la reproducción del sistema, las actividades eran improductivas. Contrariamente a lo que se suele pensar, tanto Smith como especialmente Ricardo fueron economistas contraculturales. Sus críticas mordaces al establishment de la época-aristócratas, terratenientes, nobleza, comerciantes- y su participación en política -Ricardo participó activamente en la derogación de las Leyes del Grano en 1846, unas leyes que otorgaban condiciones de mercado casi de monopolio a la producción local- les costó más que un disgusto. En su día, la economía clásica también fue una herejía del pensamiento feudal o mercantilista imperante.

Más conocida es la teoría del valor-trabajo marxista. A diferencia de Ricardo, Marx no fue tan benévolo con el papel de los capitalistas industriales y la situación de creciente empobrecimiento y malestar que se extendía entre las zonas obreras de las ciudades europeas a medida que avanzaba la revolución industrial. Su gran aportación al debate sobre 
lo que hoy llamaríamos «sostenibilidad social» del capitalismo fue la consideración de que el capitalismo es mucho más que un sistema económico, que una economía de mercado. El capitalismo es un sistema de relaciones sociales de producción, una sociedad de mercado. Una sociedad articulada alrededor de la producción y el intercambio en el mercado de todo tipo de bienes y servicios, incluidos todos los artículos necesarios para la vida. En esta nueva sociedad capitalista los trabajadores son explotados porque han perdido sus medios de subsistencia, se han convertido en un «ejército de reserva» y necesitan un sueldo para sobrevivir. La única cosa que tienen para vender y garantizar su subsistencia es su fuerza de trabajo. Además, todos los productos y servicios que necesitan están disponibles únicamente en el mercado. Sin embargo, en los mismos imperativos capitalistas Marx encuentra la semilla de su final. En su búsqueda incesante de la maximización de beneficios para reproducir su capital en forma de beneficios, los capitalistas tienen muchos incentivos para aumentar la productividad a través de la inversión en mecanización -la tecnología de aquella época-. Ello acaba por desplazar a la mano de obra, lo que reduce la fuente esencial del beneficio generado a través de la explotación. De este modo, y contraviniendo a Smith y Ricardo, los beneficios, en la medida en que son obtenidos a través de un trabajo explotado y «alineado», ya no son siempre lícitos. Los límites de la producción se establecen a través de la capacidad para generar «plusvalía» por parte del trabajo productivo, es decir, la parte de valor que corresponde a los trabajadores por su trabajo y que es «extraída» por parte de los capitalistas. Por tanto, en el lado injusto del valor, en la parte del pastel económico que es extraído injustamente, se sitúan los representantes del capital productivo o esfera de la producción -que crean la plusvalía- y del capital comercial o esfera de la circulación -que realizan la plusvalía- y que explotan el trabajo. En este contexto, los límites de los propios imperativos capitalistas -acumulación, maximización y competitividad-, así como la creciente organización y sindicalización del movimiento obrero, acabarían por crear un nuevo tipo de sociedad, donde el bien común, la propiedad y gestión pública de los medios de producción articularían unas nuevas relaciones sociales de producción. El fantasma que recorría Europa, el fantasma del comunismo, que permitiría romper las cadenas del capitalismo a través de la unión de los proletarios del mundo, debería conducir a una sociedad -en lenguaje actual- más sostenible, más justa e igualitaria. Eso sí, con un aviso a navegantes especialmente importante para el caso del desarrollo en el resto del mundo: la revolución del bien común no es posible en sistemas capitalistas poco desarrollados. A pesar de todo, el capitalismo había ejercido una función «material e histórica»: preparar al mundo para la sostenibilidad social, que solo sería posible en el comunismo.

La idea de que el valor y la justicia social de su distribución dependían de las condiciones objetivas de producción, entre ellas todas sus dimensiones económicas, como el sistema de precios, pronto pasarían a la «papelera» de la historia. En breve, una nueva dinastía asaltaría el trono de la economía: la economía neoclásica, y su visión subjetiva y marginalista del valor se estaba cocinando a fuego lento. La oposición intelectual, política y obrera al capitalismo fue creciendo a lo largo del siglo XIX. Aparecieron propuestas cooperativistas -participación obrera en la propiedad de los medios de producción-, el movimiento obrero se fue reforzando y la dinámica política cristalizó con el nacimiento de los partidos de los trabajadores en muchos países europeos. Por ejemplo, en 1900 y muy influenciado por las tesis de la Sociedad Fabiana -que defendía una tercera vía mixta o socialista, entre el capitalismo y el comunismo-, nació el Partido Laborista en el Reino Unido. Ante estos movimientos, y en unos momentos de gran expansión de las ciencias naturales y matemáticas, se empezó a fraguar la idea de una nueva economía con base matemática, lejos de la «literatura de la economía política». La consolidación de los capitalistas como una nueva y poderosa clase social, con una clara necesidad de legitimación frente a los intereses tradicionales de aristócratas, terratenientes o nobles, hizo el resto. Se empezó por justificar a los beneficios como una forma alternativa y sacrificada de no consumo. Siguiendo postulados ricardianos: los capitalistas que no utilizan sus excedentes para despilfarrar -como sí se hacía en la época feudal o mercantil-, sino que "sacrifican» este consumo para reproducir la economía, deben ser considerados como elementos no explotadores de la sociedad. En este contexto, aparecieron tres economistas, con orígenes y circunstancias muy distintas, que darían cobertura a la naciente economía neoclásica. Se trata de William Stanley Jevons (18351882), Léon Walras (1834-1910) y Carl Menger (1840-1921). Los tres son considerados los padres de la revolución marginalista, y en consecuencia de la visión neoclásica de la economía, todavía hoy muy vigente en la aproximación al hecho económico.

La base de su nueva interpretación subjetiva del valor hay que buscarla en la noción de utilidad. La utilidad expresa el valor que otorgamos a un bien o servicio, y puede comprender valoraciones objetivas o subjetivas. Es precisamente este valor que surge de la utilidad lo que determina los costes de producción, incluidos los salarios, y no al revés como establecía la teoría del valor-trabajo. Para los economistas neoclásicos el valor de una mercancía reside en la utilidad 
que tiene para su comprador, de manera que el trabajo productivo es aquel que, simplemente, genera valor, es decir que genera utilidad para alguien. La síntesis del pensamiento neoclásico fue realizada por Alfred Marshall (1842-1924). A él le debemos que la economía dejara de preocuparse por grandes cantidades de cosas -factores de producción o tecnología- y empezara a analizar pequeños aumentos incrementales, «marginales», utilizando las matemáticas y reglas de comportamiento «newtonianas». El marginalismo, la nueva teoría del valor, parte de las ideas de utilidad y escasez. Es la utilidad -noción subjetiva, no estandarizable, y variable- la que determina el valor que las personas asignan a los bienes y servicios. Por su parte, es la escasez la que determina la evolución que conferimos a la utilidad. La idea de la escasez se volvió, de repente, tan importante que acabó por explicar la propia naturaleza de la economía como ciencia. Lionel Robbins (1898-1984) -otro influyente economista neoclásico- definió la economía en términos de gestión de la escasez: «el estudio de la asignación de recursos bajo condiciones de escasez». En concreto, y para la mayoría de bienes y servicios, rige la utilidad marginal decreciente. La utilidad que conferimos a un bien o servicio disminuye a medida que esta se hace más frecuente. Y, al revés, la utilidad marginal de un bien o servicio adicional que es escaso es creciente en el tiempo. Por consiguiente, los precios se dirimen en función de la utilidad marginal que conferimos a la escasez de bienes y servicios y su evolución -o preferencias del consumidor-. A mayor escasez, mayor precio, porque asignamos mayor utilidad a un bien escaso. Lo mismo es planteable para la teoría de la producción. La productividad marginal es el efecto que genera una unidad adicional de producción sobre los costes de producción. La productividad marginal decreciente nos dice que a medida que aumentamos el número de bienes o servicios producidos sus efectos sobre los costes de producción son inferiores. En el caso del factor trabajo, el precio con el que empresario decide retribuir a sus empleados, los salarios, dependen de la productividad marginal, es decir de la valoración de una unidad de trabajo más sobre los costes de personal.

Ante los grandes desencuentros, desencajes y desigualdades «explicados» por la teoría del valor-trabajo, la economía neoclásica propone justo lo contrario: evoluciones graduales, funciones de ofertas y demandas incrementales y representables con métodos matemáticos de optimización, y una economía en equilibrio. Y, lo más importante, ahora los sistemas de precios son los verdaderos medidores del valor en una economía que alcanza equilibrios y vaciados de mercado siguiendo las fuerzas del desarrollo capitalista que conducen a la igualdad entre precio y utilidad marginal, o entre precio y coste marginal. Sin embargo, y a pesar de su «impecable» base matemática, la forma marginalista de interpretar al valor topó con una adversidad métrica. Al trasladar la idea del valor de una fuente objetiva y absoluta a una fuente subjetiva y relativa, la capacidad para medir el éxito o el fracaso de las naciones, su riqueza o su pobreza, se vio muy limitada. Además, la correcta determinación de los precios que equilibran la economía y vacían los mercados, necesita que los consumidores sean «racionalizadores perfectos de utilidad» y que no haya interferencias ni imperfecciones oligopolísticas en los mercados. Cuando esto ocurre, cuando se ha producido un intercambio en términos de precios de equilibrio, cuando el funcionamiento de los mercados es plenamente competitivo, ello nos conduce a un resultado social óptimo: nadie puede estar en mejores condiciones, nadie puede aumentar su bienestar sin empeorar el de otra persona. A esto nos referimos cuando hablamos del «primer teorema fundamental del bienestar». El equilibrio económico nos lleva al óptimo social en bienestar. Y, obviamente, en este contexto los límites de la producción casi se anulan y la función del Gobierno queda reducida a la mínima expresión. Cualquier actividad económica que genere valor, es decir, que determine utilidad, es productiva. Las únicas actividades improductivas son las vinculadas con la acción de los Gobiernos cuando estos no actúan para solventar los fallos del mercado, que es en la mayoría de las ocasiones. Por cierto, un corolario no menos relevante. Dado que capital y trabajo son retribuidos en función de sus productividades marginales, salarios y beneficios, ambos son igualmente éticos y justificables. A la desaparición de la idea de renta como extracción de valor en actividades improductivas -que con la excepción del gobierno han dejado de existir-, el marginalismo «acabó» con las «tensiones ahora injustificadas» entre capital y trabajo. En la economía neoclásica la renta como extracción de valor, como obtención de un ingreso no ganado, ya no es posible.

A pesar de que muchas de estas ideas tienen más de cien años, los fundamentos marginales de la economía neoclásica siguen en gran parte vigentes. Ya muy poca gente recuerda las funcionalidades de la teoría del valor, y la propia idea de valor ha sido "depreciada» y utilizada hasta la saciedad en infinidad de conceptos de dudosa utilidad, como valor añadido, valor para el accionista o valor comercial, e incluso ha sido eliminada de las facultades de Economía. Los estudiantes de economía aprenden que la «única y posible» forma de generar valor es a la manera marginal. Entonces por qué hablar de valor si solo hay una única manera de generarlo, y esta manera es a través de las utilidades y productividades marginales. De esta forma, la economía pasó, naturalmente y sin traumas, de la teoría del valor a la 
teoría económica. El éxito de la economía neoclásica y su «anulación» del concepto tradicional de valor ha tenido unas implicaciones determinantes en la aproximación económica al desarrollo y su vinculación con la sostenibilidad social.

\section{Economía del desarrollo y sostenibilidad social en tiempos globalizados}

Si seguimos los postulados de la economía neoclásica, el desarrollo económico, cuando se hace con las condiciones correctas de competencia, conlleva como consecuencia el bienestar social. No importa cuál es la forma de este desarrollo, ni si el modelo de crecimiento es creativo o extractivo, si se basa en la creación de riqueza o la extracción de rentas. Lo que sí importa es el momento del desarrollo económico. Gracias a las investigaciones realizadas por Simon Kuznets (1901-1985) durante las primeras décadas del siglo XX, ambas magnitudes establecen una relación en forma de $U$ invertida -la denominada Ley de Kuznets-. La idea básica de esta relación es que, en las fases iniciales del desarrollo económico, es necesario un cierto grado de desigualdad porque la «acumulación originaria» del capital lo necesita para desarrollar el proceso de ahorro-inversión y su translación a la actividad productiva. Sin embargo, a partir de un cierto grado de desarrollo, las ganancias del crecimiento económico y la creación de empleo se distribuyen hacia todos los agentes económicos y ejercen un «efecto goteo» positivo hacia el conjunto de la sociedad. Esta es la teoría que sustentó la extraordinaria y excepcional fase de crecimiento económico y reducción de la desigualdad que experimentó Occidente, o mejor dicho, el Occidente blanco y masculino, después de la Segunda Guerra Mundial y hasta la primera crisis del petróleo en 1973 «o los 30 gloriosos». Según esta aproximación, la política económica no debe preocuparse por la desigualdad, y lo que debe hacer es desarrollar políticas de oferta y demanda que impulsen las fuentes del crecimiento económico. La Escuela de Chicago, donde se guarda el jarrón de las esencias del mainstream neoclásico, ha sido la gran defensora de esta argumentación.

Una vez que los mercados alcanzan la expansión y las economías entran en crecimiento y desarrollo, es solo cuestión de tiempo que el crecimiento se distribuya y sus efectos goteo lleguen a todo el mundo. Si además las economías siguen abriendo sus mercados, se especializan siguiendo los criterios de la ventaja comparativa, y participan del proceso de globalización, las ganancias, siempre positivas, del comercio internacional de bienes y servicios continuarán impulsando vientos de cola a la expansión de los mercados internos y las economías nacionales. Como nos advierte el modelo de Samuelson-Stolper, el círculo virtuoso de la prosperidad material se alcanza cuando con las ganancias del comercio internacional favorecen a los factores de producción más intensivos en cada país (el trabajo en los países pobres y el capital en los países ricos), y a través de las ganancias de riqueza generadas se pueden instaurar políticas de movilidad y capacitación para que la dinámica positiva se extienda también a los trabajadores menos cualificados y perjudicados en los países ricos. Sin embargo, esta aproximación pronto recibió fuertes críticas, especialmente las procedentes de los países pobres. Ahora sí. Nos volvemos a encontrar con nuestros protagonistas de la introducción.

Arthur Lewis justificó la existencia de un campo económico llamado economía del desarrollo porque el contexto de los países emancipados en África, Asia o América Latina durante los inicios de la segunda mitad del siglo Xx no tenía nada que ver con el Manchester del siglo XIX. Como resultado de la Revolución Industrial, el mundo occidental tenía un nivel de desarrollo muy superior, de manera que la gran distancia por recorrer-denominó a estos países como subdesarrollados o en vías de desarrollo- justificaba un nuevo campo económico. Lewis reconoció la dualidad, la diferencia entre las economías formales e informales, en los países pobres, de manera que, contrariamente a la opinión mayoritaria, prescribió que el desarrollo industrial necesitaría de un «gran impulso» procedente del sector público y la ayuda financiera internacional. Su asunción de los fallos del mercado en los países pobres estaba relacionada con la idea de que, en economías duales, el salto a la industrialización solo se puede dar de manera integral, generando un gran conjunto de sinergias entre las propias actividades industriales. Siguiendo su consejo, Ghana y muchos otros países africanos lo intentaron. Pero la economía, la política y las instituciones se vincularon de manera fatal para el desarrollo. Aparecieron incentivos perversos, la corrupción y los típicos excesos de planificación. Otros países, como Corea del Sur o los Tigres Asiáticos fueron mucho más cautelosos con la protección y los incentivos a la industria nacional, y lo consiguieron, demostrando -como nos han evidenciado ampliamente Daron Acemoglu y James Robinson- la importancia decisiva del papel de las instituciones sobre el desarrollo.

En América Latina, André Gunder Frank y Raúl Prebisch también hicieron avanzar significativamente las ideas sobre el desarrollo. Frank ideó la teoría de la dependencia para demostrarnos que el comercio perjudica a los países pobres. 
Especializados en la producción de productos agrícolas o materias primas, los países pobres tienen sus economías monopolizadas por grandes corporaciones internacionales que «explotan" sus recursos y dirigen toda la actividad económica en función de sus intereses. A través de este poder de mercado, el comercio internacional empobrece todavía más a los países de la «periferia» del sistema a favor de los países del «centro» del capitalismo mundial. Prebisch observó que el comercio internacional empeoraba los "términos del intercambio", que siempre eran favorables a los productos de los países ricos. A medida que los países pobres colocan sus productos y crecen, la relación de intercambio siempre favorece al país rico que, comparativamente, tiene los productos y servicios con mayor valor añadido. Contraviniendo el "establishment neoclásico», ambos convinieron en señalar los graves peligros que corrían los países pobres con la integración al comercio internacional de base capitalista mundial. Sin embargo, sus soluciones difirieron ostensiblemente. Prebisch recomendó la diversificación y las políticas de substitución de importaciones para crear una fuerte base productiva nacional que fomentara un desarrollo «endógeno». Por su parte, Frank tenía un recetario mucho más radical, y su respuesta era de corte marxista: tomar el poder y crear sistemas socialistas de gestión económica que acabaran con la explotación.

Con todo, llegamos a la década de 1970, y el mundo cambió. De hecho, como las investigaciones empíricas de Kuznets y sus discípulos se desarrollaron en la edad de oro del crecimiento, sus resultados parecen «demasiado identificados con los datos». En investigaciones posteriores, como la realizada por Thomas Piketty, se ha demostrado sobradamente que la relación inversa entre desarrollo y desigualdad ya no es tan evidente, e incluso que los determinantes de la etapa de mayor prosperidad e igualdad en las clases medias -insisto, en hombres blancos- del Occidente capitalista estarían más vinculados con el papel intervencionista del Estado en la economía, con la creación de un sistema económico mixto, y más especialmente con sus políticas fiscales redistributivas. Esta visión sobre el dilema entre el desarrollo económico y la desigualdad ha sido la que han aplicado distintas administraciones y Gobiernos en todo el mundo y durante varias etapas. Por ejemplo, fue la base de las políticas neoliberales que la Administración Reagan o el Gobierno de Thatcher impulsaron en EE. UU. y el Reino Unido, respectivamente, durante la década de los ochenta, y que tuvieron continuidad temporal, ampliación territorial y vigencia ideológica durante varias décadas posteriores. Siguiendo los postulados de la Escuela de Chicago, la idea básica de estas aproximaciones es que la política económica debe preocuparse básicamente por generar crecimiento económico, generalmente a través de políticas de subvención a la oferta y políticas monetarias, mientras que las políticas de demanda y, muy especialmente, las políticas fiscales progresivas, ambas tan típicamente keynesianas, deberían pasar a mejor vida. Los puntos calientes de esta aproximación económica siempre han sido la expansión del capitalismo a través de la globalización, la desregulación y liberalización -el desmantelamiento de las restricciones a los mercados y sectores sensibles- y los impuestos, y especialmente los tipos impositivos aplicados a las clases -personas y empresas- privilegiadas.

Estos fueron los fundamentos de la etapa de hiperglobalización que empezó en las décadas de 1980 y 1990. La visión neoliberal del desarrollo económico incentivó activamente la participación directa de las economías pobres en el comercio internacional. Además, estas economías debían participar de todo el recetario neoclásico para evitar la presencia «improductiva» del Gobierno en la economía. Únicamente situando a los mercados y a las empresas, especialmente a las grandes corporaciones, en una posición dominante, globalizando, desregulando y liberalizando sectores clave, como el energético, los transportes o las finanzas, reduciendo la intervención del Estado y, especialmente, rebajando los impuestos, el círculo virtuoso de la globalización alcanzaría su plenitud.

Como han venido señalando reiteradamente una gran cantidad de investigaciones, estas políticas no acabaron de impulsar el crecimiento económico en Occidente que, a largo plazo, no ha vuelto a alcanzar los valores de, cómo no «los 30 gloriosos», y especialmente no han conseguido de ningún modo mejorar ostensiblemente la prosperidad material media, especialmente si la relacionamos con los deciles o centiles más ricos. En los países pobres es cierto que la integración económica mundial ha traído resultados favorables, como demuestra el aumento espectacular de la riqueza y la diversificación económica de los Tigres Asiáticos o de la economía de China. Pero también se han ido acumulando sonoros fracasos en muchas iniciativas ideadas para que el desarrollo económico generara menor pobreza o más bienestar en África o América Latina. De hecho, las propias políticas neoliberales que acabaron por desregular excesivamente las finanzas globales crearon un «capitalismo de casino» que sembró las semillas de la destrucción. La gran crisis financiera y económica internacional acabó de golpe con muchas de las posibilidades de encaje entre el desarrollo económico y la sostenibilidad social. El «malestar» existente en muchas partes del mundo con esta forma específica de globalización es un buen ejemplo de ello. 
En resumen, se ha trabajado en beneficio de unos pocos, buscando modelos de apropiación de rentas -en lugar de modelos basados en creación de riqueza- y presentando una falsa dicotomía, un falso dilema, entre crecimiento e igualdad. No existe tal dilema. La buena economía lo señala claramente: es recomendable incentivar modelos de crecimiento intensivos que generen riqueza a través de fuentes adecuadas, entre ellas una mayor atención al cómo se comparte la prosperidad material generada. Debemos retornar los preceptos clásicos sobre cómo se crea, distribuye y reparte el valor. Las economías suelen crecer y desarrollarse a través de las mejoras de productividad que determinan unos mayores y mejores flujos de tecnología y conocimiento que, a su vez, se nutren de amplios programas de investigación básica, generalmente de dominio público. A su vez, el entorno institucional, la forma que toma la democracia económica, con sus fundamentos de derecho, protección de la propiedad, libertad de empresa, prácticas para evitar la corrupción, políticas impositivas adecuadas o políticas de defensa de la competencia, también son fundamentales para la generación de un bienestar común, un bienestar para todos. Y para llegar a esta prosperidad material, las nuevas contribuciones de la buena economía nos señalan claramente que los mercados por sí solos no son suficientes para asegurar la prosperidad compartida y duradera, especialmente en presencia de bienes públicos, asimetrías de información o cuando la relación coste-beneficio social se aleja mucho de la relación coste-beneficio individual, como sucede en el caso del medio ambiente. La intervención pública, un "Estado emprendedor», no solo como corrector de los fallos del mercado, sino como creador de riqueza, es imprescindible para llegar a una translación efectiva entre desarrollo económico y sostenibilidad social. Eso sí, en pleno siglo XXI, las políticas y formas del Gobierno no pueden ser las mismas de siempre. Nuevos tiempos, nuevo gobierno.

\section{Conclusión: ¿encajan los ODS con la nueva economía del valor sostenible?}

Acabamos de constatar que, en la economía de hoy, únicamente es posible plantearse un encaje entre el desarrollo económico y la sostenibilidad social a partir de una nueva aproximación analítica y de economía política. Como acabamos de constatar, debemos recuperar los preceptos objetivos de la teoría del valor, y adaptarlos a las necesidades de la sostenibilidad en el siglo XXI. Para ello, es absolutamente necesaria la intervención de un sector público que haga algo más que corregir los fallos del mercado. Debe ser productivo. Debe aprender a valorizar su conocimiento, y muy especialmente a contabilizar y rentabilizar correctamente su creación de riqueza. Por su parte, los agentes económicos y sociales deben avanzar hacia un nuevo contrato social donde la sostenibilidad económica se intercambie con la sostenibilidad social y ambiental. En el contexto de los movimientos sociales y políticos que se impulsaron ante la destrucción económica, social y ambiental vinculada con la última depresión económica, Naciones Unidas consiguió aglutinar a todas sus redes alrededor de una nueva Agenda 2030 y la idea de alcanzar 17 objetivos de desarrollo sostenible (ODS), que incluyen 169 metas y 234 indicadores. Ante esta loable -dicho sea de paso- iniciativa, la pregunta es irremediable: ¿encajan los actuales ODS con la nueva economía del valor sostenible que se está configurando científicamente para alinear mejor el desarrollo económico con la sostenibilidad social? Mi respuesta es que no. Mi negativa tiene una base conceptual y empírica. Empíricamente, y aunque los ODS son de 2015, es evidente que han sido de muy poca utilidad para cambiar el signo de los vencedores de la globalización. En la figura 1 se relacionan la participación de los salarios y el capital (capitalización de empresas nacionales) sobre el PIB, y la evolución del PIB mundial entre 1991 y 2019. Los datos han sido extraídos del Banco Mundial. En la figura se observa claramente cómo, a pesar del significativo avance del PIB mundial en las últimas tres décadas, la participación de los salarios se mantiene muy estable en valores reducidos. De este modo, se constata que el gran beneficiado de la globalización han sido las empresas y su capital. En los últimos años, esta tendencia no se ha visto alterada. 
Figura 1. ¿Quién ha sido el principal beneficiado de los rendimentos de la hiperglobalización?

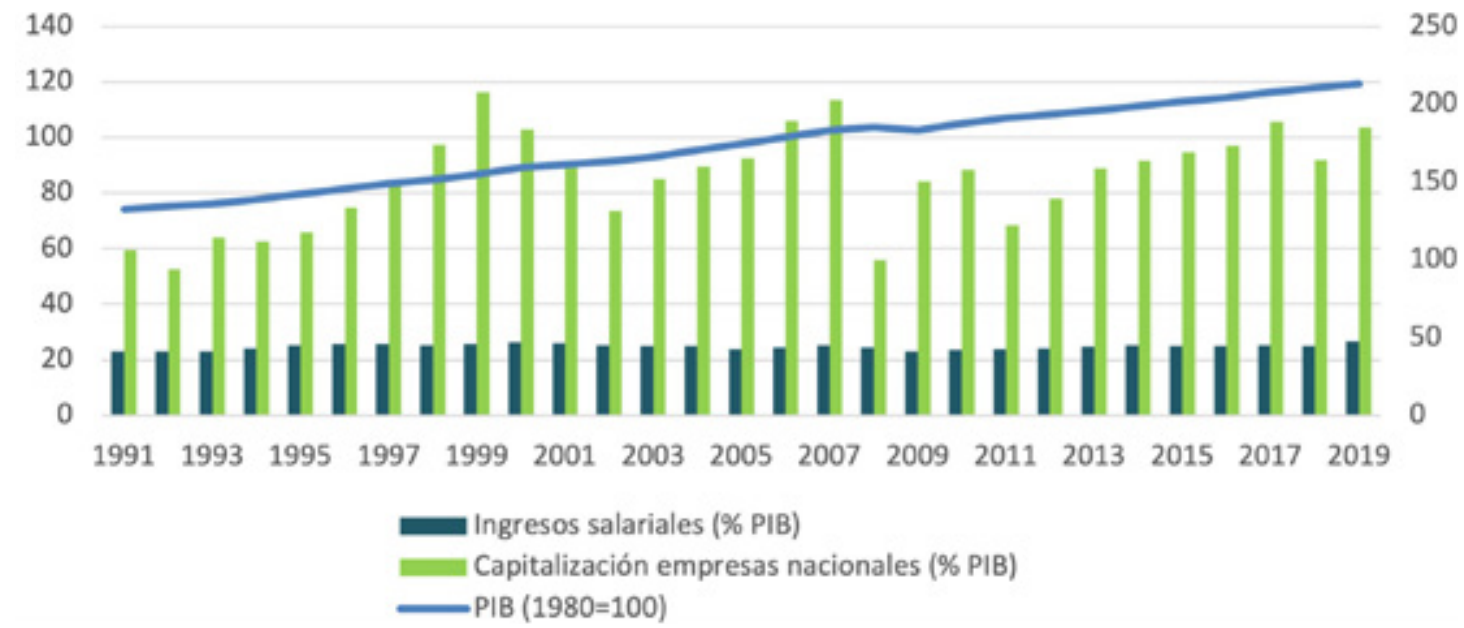

De manera similar, en la figura 2 se relaciona la dinámica del PIB y del PIB per cápita mundial con dos indicadores de pobreza: uno relativo a la pobreza extrema (menos de 1,90 dólares constantes y en poder de paridad de compra de 2011) y otro relativo a la pobreza (menos de 5,50 dólares) entre 1981 y 2019. Los resultados obtenidos nos señalan una creciente divergencia entre los avances del PIB y el PIB per cápita, lo que nuevamente reflejaría unos muy débiles efectos de la globalización económica sobre el bienestar material tangible e intercambiable que representa el PIB. Y, desde el punto de vista de la pobreza, se observan notables reducciones relativas a la pobreza extrema, y reducciones mucho menores en el caso de la pobreza no extrema. Análogamente, los ODS parece que han hecho poco para reforzar el vínculo entre desarrollo económico y bienestar social, aunque con la pobreza extrema sí que se aprecia algún avance significativo.

Figura 2. ¿Es posible un desarrollo económico y social sostenible en el mundo?

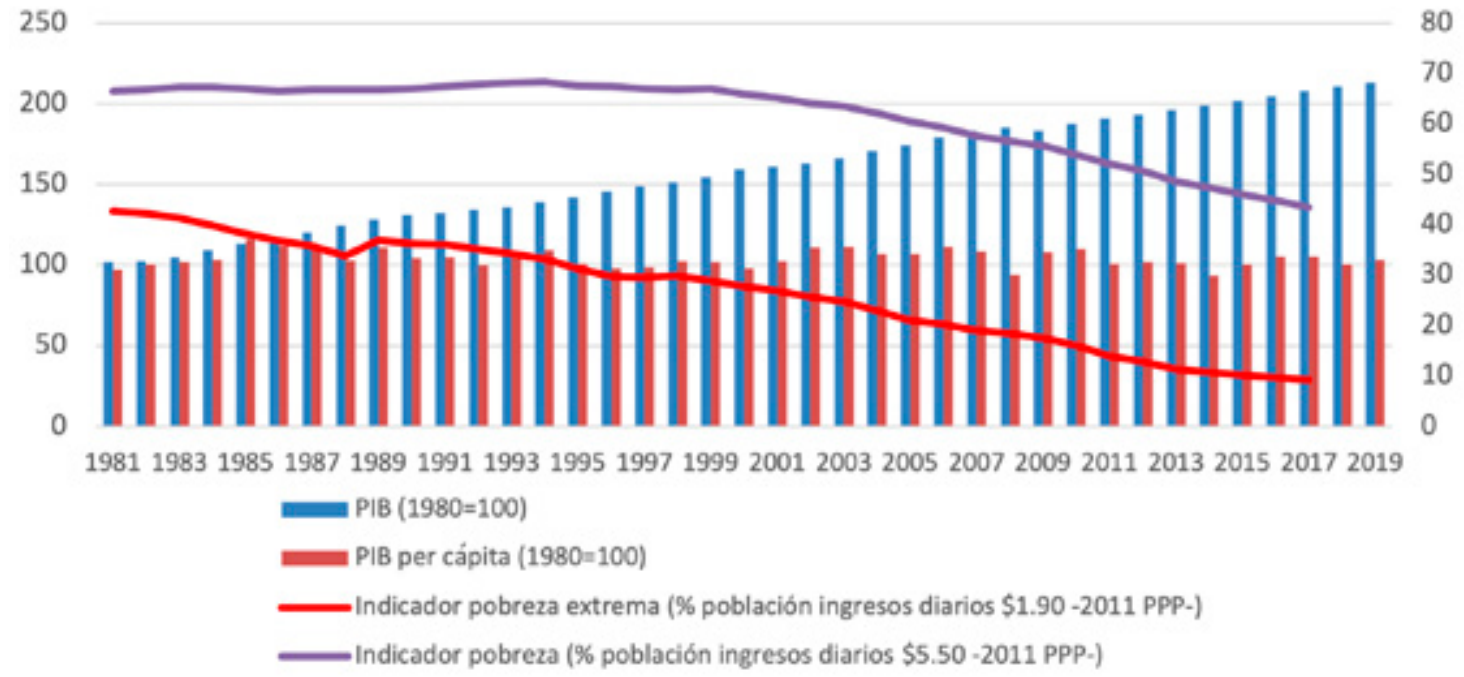

Mi segunda reticencia es de carácter conceptual, sobre los fundamentos económicos y metodológicos de los ODS. Una revisión de los documentos publicados y un análisis de los indicadores establecidos para conseguir los objetivos me reafirman en esta reticencia. No he sido capaz de encontrar el fundamento económico de los ODS. No sé sobre qué teoría o visión del desarrollo económico se sustentan. ¿Qué descripción del mundo económico hacen los ODS? ¿Cuáles son los problemas económicos que pretende resolver? ¿Existen agentes, estructuras de mercado o políticas 
económicas que deben cambiar? Tampoco he sido capaz de encontrar algunos aspectos clave que la literatura ha identificado como esenciales para reforzar el vínculo entre desarrollo económico y sostenibilidad social, como el papel de la libertad o la democracia económica, el rol de las instituciones, o el encaje con un concepto económicamente mucho más trabajado y solvente, como el de "desarrollo humano». Un ejemplo, a mi entender, claramente ilustrativo. En el documento oficial en castellano de los ODS, la palabra «impuesto» aparece una vez, las palabras «fiscalidad» y «capital público», ninguna, y la palabra "gasto público», tres veces. ¿Cómo se pretende articular una generación de valor económico sostenible socialmente sin impuestos? ¿Cuál es el mecanismo de generación de ingresos y capitales públicos que son necesarios para el desarrollo de la nueva economía del valor sostenible? Metodológicamente, sigo sin entender muy bien la relación entre instrumentos y objetivos, al estilo de la formulación típica de la política económica. ¿Qué sucede con las posibles contradicciones -trade off-entre las distintas dimensiones de la sostenibilidad? Por ejemplo, un objetivo de trabajo decente y crecimiento económico, como la creación de empleo en la industria del carbón, puede entrar en clara contradicción con un objetivo de naturaleza social o ambiental. ¿Cómo se construye el indicador sintético de desarrollo sostenible? ¿Su modelo analítico es reflexivo o formativo? A mi entender los ODS necesitan una revisión en profundidad, tanto conceptual como metodológicamente. Uno podría tender a pensar que esto es irrealizable y, además, imposible. Aunque viendo la receptividad y la mixtura entre escuelas y corrientes de análisis y el pensamiento económico durante los últimos años, yo ya no me atrevo con ninguna predicción. Eso sí, por coherencia, la co-creación debe llevarse, en primer lugar, al terreno económico. Sería una gran oportunidad para vencer a uno de nuestros dogmas preferidos: Oeconomia non facit saltum. Creo que valdría la pena intentarlo.

\section{Referencias bibliográficas}

ACEMOGLU, D.; ROBINSON, J. A. (2012). Por qué fracasan los países. Los orígenes del poder, la prosperidad y la pobreza. Barcelona: Deusto, Planeta.

BANERJEE, A. V.; DUFFLO, E. (2020). Buena Economía para tiempos difíilles. En busca de mejores soluciones a nuestros mayores problemas. Barcelona. Taurus / Penguin Random House.

KISHTAINY, N. (2019). Breve historia de la economía. Barcelona: Biblioteca Nueva.

MAZZUCATO, M. (2019). El valor de las cosas. Quién produce y quién gana en la economía global. Barcelona: Taurus, Penguin Random House.

MEISKINS-WOOD, E. (2017). El origen del capitalismo. Una mirada de largo plazo. Madrid: Siglo XXI.

MILANOVIC, B. (2020). Capitalismo, nada más. El futuro del sistema económico que domina el mundo. Barcelona: Taurus, Penguin Random House.

NACIONES UNIDAS, CEPAL (2019). La agenda 2030 y los Objetivos de Desarrollo Sostenible. Una oportunidad para América Latina y el Caribe. Santiago de Chile: Naciones Unidas.

PIKETTY, T. (2014). El capital en el siglo XXI. Barcelona: RBA.

PIKETTY, T. (2019). Capital e ideología. Barcelona: Deusto, Planeta.

STIGLITZ, J. E. (2020). Capitalismo progresista. La respuesta a la era del malestar. Barcelona: Taurus, Penguin Random House.

TIROLE, J. (2017). La economía del bien común. Barcelona: Taurus, Penguin Random House.

WHITE, L. H. (2014). El choque de ideas económicas. Los grandes debates de política económica de los últimos cien años. Barcelona: Antoni Bosch. 
Cita recomendada: TORRENT-SELLENS, Joan. ¿Es posible un desarrollo económico y social sostenible? Una nota crítica sobre el «valor» de los ODS. Oikonomics [en línea]. Noviembre 2021, n. 16. ISSN: 2339-9546. DOI: https://doi.org/10.7238/o.n16.2115

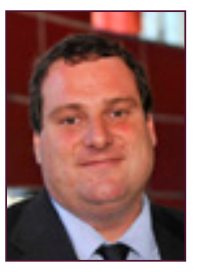

\section{Joan Torrent-Sellens}

jtorrent@uoc.edu

\section{Catedrático de Economía en los Estudios de Economía y Empresa de la UOC}

Director del grupo interdisciplinar de investigación, sobre las TIC, i2TIC (https://i2tic.research.uoc.edu/es/). Especialista en el análisis económico de la transformación digital y la economía del conocimiento, temática sobre la que ha publicado 65 libros y capítulos de libro, y 115 artículos en revistas de investigación y de divulgación indexadas.

Los textos publicados en esta revista están sujetos -si no se indica lo contrario- a una licencia de Reconocimiento 4.0 Internacional de Creative Commons. Puede copiarlos, distribuirlos, comunicarlos públicamente, hacer obras derivadas siempre que reconozca los créditos de las obras (autoría, nombre de la revista, institución editora) de la manera especificada por los autores o por la revista. La licencia completa se puede consultar en https://creativecommons.org/licenses/by/4.0/deed.es_ES.

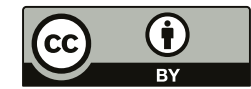

